\title{
Pengembangan Bentuk Soal Tipe Benar-Salah dalam Penilaian Kelas Sekolah Menengah Pertama
}

\author{
Aswin H. Mondolang, Cosmas Poluakan, Satyano W. Mongan, Dewi S. Umacina \\ Universitas Negeri Manado, Indonesia \\ Iaswinmondolang@yahoo.co.id
}

\begin{abstract}
This research is motivated by the existence of speculation of students in answering the true-false type of questions. The purpose of this study was to develop questions true-false type in consept of physics on work and simple machines in class VIII SMP which can minimize speculation. This research and development uses a Research \& Development $(R \&$ D) model from SivasailamThiagarajan, Dorothy S. Semmel, and Melvyn I. Semmel consisting of 4 main drums determined (defining), design (design), development (development), and spread (spread). Data collection was obtained through interviews, questionnaire instruments and student grades. The results of validation by evaluation experts and material through questionnaires obtained an average percentage of $92.5 \%$ with a valid category. And from the results of trying to 32 students, the questions developed can minimize student speculation in answering questions. Thus, a class that uses the form of B-S questions that are equipped with $Y$-TY options can measure students more objectively than the B-S type questions without $Y$-TY choices.
\end{abstract}

Keywords: True-false type; work and simple machines

\begin{abstract}
Abstrak
Penelitian ini dilatarbelakangi oleh adanya spekulasi siswa dalam menjawab soal objektif tipe benar-salah. Tujuan dari penelitian ini adalah untuk mengembangkan soal objektif tipe benar-salah dalam penilaian kelas materi fisika usaha dan pesawat sederhana pada siswa kelas VIII SMP yang dapat meminimalisir spekulasi. Penelitian ini menggunakan model research \& development (R\&D) dari Sivasailam Thiagarajan, Dorothy S. Semmel, dan Melvyn I. Semmel (I974) yang terdiri dari 4 tahap utama yaitu define (pendefinisian), design (perancangan), develop (pengembangan), dan disseminate (penyebaran). Data penelitian diperoleh melalui teknik wawancara, instrumen angket, dan nilai siswa. Validasi instrumen oleh pakar evaluasi dan pakar materi melalui instrumen angket diperoleh rerata persentase sebesar $92,5 \%$ dengan kategori valid. Data nilai siswa dari hasil uji coba kepada 32 siswa, soal yang dikembangkan dapat meminimalisir spekulasi siswa dalam menjawab soal. Dengan demikian penilaian kelas yang menggunakan bentuk soal tipe B-S yang dilengkapi dengan pilihan Y-TY dapat mengukur pemahaman siswa secara lebih objektif dibandingkan dengan bentuk Soal tipe B-S tanpa pilihan Y-TY.
\end{abstract}

Keywords: Bentuk soal tipe benar-salah; usaha dan pesawat sederhana 


\section{Pendahuluan}

Untuk mengetahui pencapaian tujuan pembelajaran maka perlu dilakukan evaluasi. Arikunto (2016) menyatakan bahwa evaluasi adalah kegiatan pengumpulan data untuk mengukur sejauh mana tujuan sudah tercapai (Arikunto, S., 2016). Salah satu aspek penting dalam evaluasi pembelajaran adalah penilaian, karena penilaian hasil belajar sangatlah diperlukan untuk mengetahui sejauh mana keberhasilan seorang guru dalam menyajikan materi pelajaran serta sejauh mana peserta didik telah menyerap materi pelajaran yang diberikan oleh guru. Selain itu beberapa tujuan atau fungsi penilaian yang dilakukan oleh guru di antaranya yaitu, untuk menentukan siswa yang naik atau tinggal di kelas, untuk memilih beberapa siswa yang berprestasi dalam mendapatkan beasiswa dan lain sebagainya (Arikunto, 2016).

Karena penilaian hasil belajar adalah bagian dari penilaian kelas yang merupakan kegiatan yang dilaksanakan oleh guru dalam rangka pengambilan keputusan tentang pencapaian hasil belajar siswa setelah mengikuti proses pembelajaran (Uno dan Koni, 20I2), maka dalam implementasinya dapat dilakukan dengan teknik tes maupun non tes (Arikunto, 20I6, Mardapi, 20I4). Teknik tes dapat dilakukan dengan pemberian soal kepada peserta didik, soal tersebut bisa berbentuk soal subjektif maupun soal objektif, dimana keduanya masing-masing memiliki kekurangan dan kelebihan. Namun disini peneliti hanya akan membahas mengenai soal objektif.

Kemampuan setiap siswa dalam mengerjakan kedua jenis tes tersebut berbeda-beda. Bentuk-bentuk tes yang digunakan dalam evaluasi belajar menuntut kemampuan siswa untuk dapat menyusun, mengemukakan, memaparkan dan memadukan gagasan-gagasan yang telah dimilikinya setelah melalui proses pembelajaran di kelas. Kemampuan yang diharapkan ialah siswa mampu mengembangkan kemampuannya dalam menganalisa dan mengerjakan soal yang diberikan, sehingga dapat diketahui tingkat pemahaman tentang materi yang telah diberikan guru.

Fisika merupakan salah satu mata pelajaran yang diajarkan di Sekolah Menengah Pertama maupun Sekolah Menengah Atas. Fisika adalah cabang IPA yang mempelajari gejala-gejala alam. Konsep-konsep dan prinsipprinsip dalam fisika saling terkait, misalnya konsep energi terkait dengan gerak, gaya, kalor, bunyi, getaran, gelombang dan sebagainya. Energi dapat diubah menjadi berbagai macam bentuk energi lain (Purjiyanta, 2007).

Dari hasil penelitian terdahulu yang dilakukan oleh Suwuhang (2018) yang mengangkat judul "Analisis Kecenderungan Mengerjakan Bentuk Tes Uraian Dan Tes Objektif Materi Fisika Besaran Dan Satuan Serta Kinematika Gerak Pada Siswa Kelas X SMA Negeri I Tagulandang”. Hasil penelitian tersebut menyatakan bahwa siswa cenderung memilih tes objektif. Hal ini dapat dilihat dari hasil pekerjaan siswa, kecenderungan mereka memilih tes objektif karena kesenangan dalam menyelesaikan soal yang mudah dipahami, bahkan siswa yang tidak menguasai materi dapat memilih jawaban secara acak karena pilihan jawaban sudah tersedia. (Suwuhang, Ketlin F., 2018).

Berdasarkan observasi yang dilakukan peneliti di SMP Negeri 4 Tondano, peneliti mendapati bahwa para siswa sudah mengetahui berbagai bentuk soal objektif dikarenakan pada setiap pelaksanaan Ujian Akhir Semester (UAS) mereka diberikan tes berupa soal-soal berbentuk Essay maupun objektif. Dan untuk soal objektif pun semua tipe soal diberikan seperti pilihan ganda, benar-salah (true-false), menjodohkan (matching test) dan isian (completion test). Akan tetapi dalam menjawab soal-soal bentuk objektif siswa sering melakukan spekulasi atau menerka. Perilaku berspekulasi dalam menjawab soal objektif pilihan ganda (multiple choise) merupakan suatu kelemahan dari bentuk soal pilihan ganda termasuk di dalamnya bentuk soal tipe Benar-Salah (B-S). Khususnya untuk soal objektif tipe benar-salah kelemahannya adalah ketika para siswa menjawab secara tebakan atau berspekulasi, maka para siswa akan memiliki kemunginan menjawab benar adalah 50\%. Akibatnya akan sulit bagi guru atau penilai untuk mengukur kemampuan yang sesungguhnya dimiliki oleh para siswa. Namun di samping kelemahan yang ada, bentuk soal tipe Benar-Salah juga memiliki 
sejumlah kelebihan seperti dapat mewakili materi pelajaran yang lebih komprehensif, mudah penyusunannya, dan juga mudah dalam pengolahannya (Widoyoko, 2012). Pendapat yang sama juga dikemukakan oleh Sudaryono (2012) bahwa bentuk soal tipe Benar-Salah memiliki kelebihan seperti mudah menyusunnya serta dapat mencakup materi yang lebih komprehensif (Sudaryono, 20I2). Oleh karena itu, peneliti ingin mengembangkan bentuk tes objektif tipe benar-salah yang dapat meminimalisir spekulasi atau aspek menerka yang sering dilakukan oleh siswa.

\section{Metode}

Penelitian ini dilaksanakn di SMP Negeri 4 Tondano. Subjek uji coba pada penelitian ini adalah siswa kelas VIII A yang bejumlah 32 orang. Penelitian ini merupakan penelitian dan pengembangan (R \& D). Model pengembangan yang digunakan dalam penelitian ini mengikuti alur Sivasailam Thiagarajan, Dorothy S. Semmel, dan Melvyn I. Semmel (1974) yang terdiri dari 4 tahap utama yaitu Define, Design, Develop, dan Disseminate (4-D) atau diadaptasikan menjadi model 4-P, yaitu pendefinisian, perancangan, pengembangan, dan penyebaran (Thiagarajan, S., Semmel, Dorothy S., \& Semmel, Melvyn I., I974,).

Langkah-langkah dalam penelitian ini dimulai dari tahap pertama (tahap pendefinisian) yang mana didalamnya terdapat bebarapa langkah, yaitu analisis awal, analisis peserta didik, analisis tugas, analisis konsep, dan analisis tujuan pembelajaran. Tahap kedua dari penelitian ini adalah tahap perancangan. Dalam tahap perancangan terdapat beberapa langkah diantaranya yaitu, penyusunan tes, pemilihan format, dan desain awal. Tahap ketiga adalah tahap pengembangan, dimana dalam tahap ini dilakukan validasi produk dan uji coba produk. Dan tahap terakhir dari penelitian dan pengembangan ini adalah tahap penyebaran.

Dalam penelitian ini terdapat dua jenis data yaitu data kualitatif dan data kuantitatif. Data kualitatif didapat dari hasil wawancara antara peneliti dengan para ahli/pakar, dimana datanya berupa tanggapantanggapan, masukan maupun komentar dari ahli/ pakar. Sedangkan data kuantitatif didapat dari pengisisan angket oleh para ahli dan nilai hasil belajar yang diperoleh subjek uji coba. Subjek uji coba dalam penelitian ini adalah siswa di SMP Negeri 4 Tondano kelas VIII A.

Instrument yang digunakan oleh peneliti disesuaikan dengan jenis datanya. Untuk jenis data kualitatif peneliti menggunakan buku catatan/lembar pertanyaan dan kamera. Dimana buku catatan/lembar pertanyaan digunakan untuk menuliskan pertanyaan-pertanyaan dan jawaban dari hasil wawancara antara peneliti dengan ahli/pakar. Sedangkan untuk jenis data kuantitatif peneliti menggunakan angket dan nilai hasil belajar siswa.

\section{Hasil dan Pembahasan}

Berdasarkan hasil penelitian daripenjelasan diatas terdapat Enam contoh soal (50\%) dari dua belas soal yang dikembangkan yaitu sebagai berikut:

1. Mega mendorong kursi dengan gaya $\mathrm{F}=20 \mathrm{~N}$, sehingga kursi tersebut mengalami perpindahan sejauh $\Delta s=3 \mathrm{~m}$. Jika Mega mendorong kursi dengan gaya $\mathrm{F}=10 \mathrm{~N}$, maka kursi akan mengalami perpindahan sejauh $\Delta s=1,5 \mathrm{~m}$. [B-S; Y $-\mathrm{TY}]$ 
2. Perhatikan gambar berikut ini:

(a)

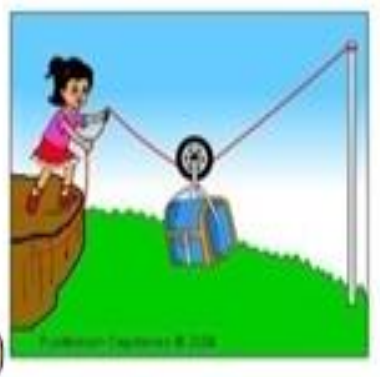

(b)

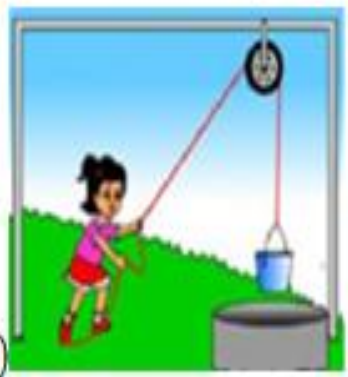

Gambar (a) dan (b) merupakan contoh katrol. Dari gambar (a) dan(b) dapat diketahui bahwa gambar (b) merupakan contoh katrol bebas. [B-S; Y-TY]

\section{Perhatikan gambar berikut ini!}

(a)

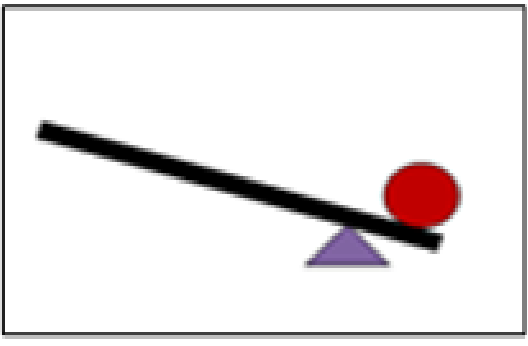

Erik ingin memindahk an batu dengan berat $30 \mathrm{~kg}$ dengan menggunakan tuas yang panj angnya $3 \mathrm{~m}$ sebagai pengungkit. Jika Erik membuat jarak antara titik tumpu dan titik beban seperti pada gambar di atas, maka cara paling mudah untuk memindahkan batu adalah gambar (a). [B - S ; Y - TY]

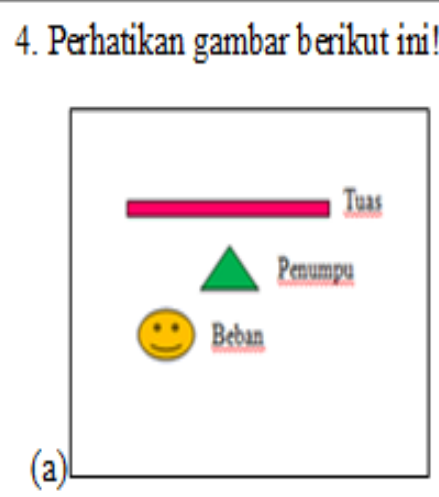

(b)

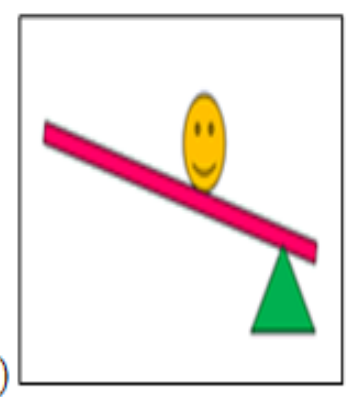

(c)

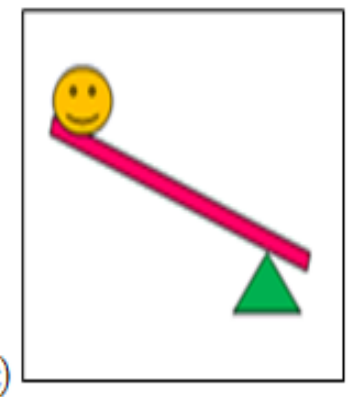

Jika benda-benda pada gambar (a), disusun untuk menghasilkan pesawat Sederhana tuas atau pengungkit jenis pertama yang konsep atau prinsip kerjanya seperti gunting, maka susunan yang sesuai adalah gambar (c). [B - S ; Y - TY] 


\section{Perhatikan gambar berikut!}

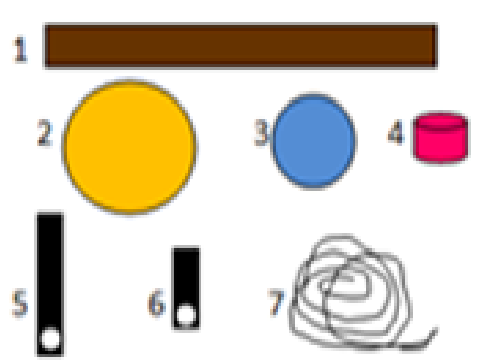

$\begin{array}{ll}\text { Ket: } & \\ \text { 1. } & \text { Balok tempat katrol digantung } \\ \text { 2. } & \text { Roda katrol besar } \\ \text { 3. } & \text { Roda katrol kecil } \\ \text { 4. } & \text { Beban } \\ \text { 5. } & \text { Balok pengait roda katrol panjang } \\ \text { 6. } & \text { Balok pengait roda katrol pendek } \\ \text { 7. } & \text { Tali }\end{array}$

Jika benda-benda pada gambar di atas, disusun untuk menghasilkan katrol majemuk yang memiliki keuntuntungan mekanis sebesar 4 , maka susunan yang sesuai adalah gambar (b). [B-S ; Y - TY]

(a)

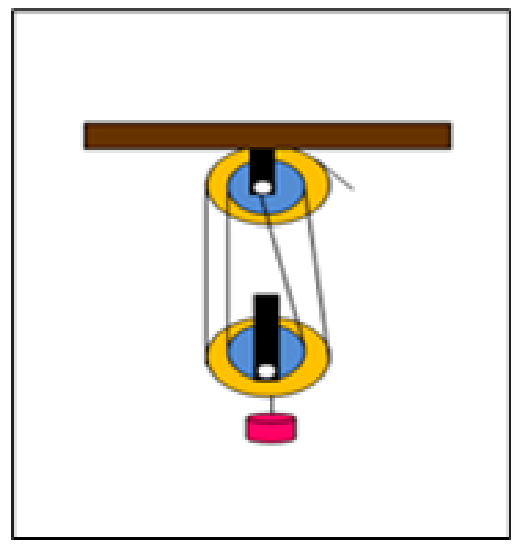

(b)

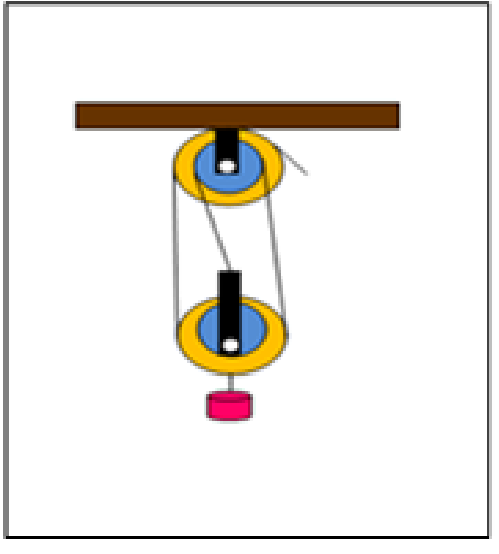

6. Besar beban yang ditarik oleh katrol pada gambar di bawah ini adalah $25 \mathrm{~N}$. [B -S; Y -TY]

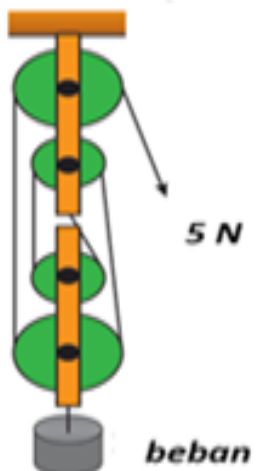

Soal-soal yang dikembangkan telah melalui validasi oleh ahli/pakar evaluasi (VI) dan ahli/pakar materi (V2) seperti ditunjukkan pada Tabel I di bawah ini: 
Tabel I. Hasil Validasi Ahli/Pakar

\begin{tabular}{|c|c|c|c|c|c|}
\hline \multirow[t]{2}{*}{ Indikator } & \multicolumn{2}{|c|}{ Skor } & \multirow[t]{2}{*}{$\bar{X}$} & \multirow[t]{2}{*}{$\%$} & \multirow[t]{2}{*}{ Kriteria } \\
\hline & VI & $\mathrm{V} 2$ & & & \\
\hline Aspek Materi & 3,9 & 3,8 & 3,85 & 96,25 & Valid \\
\hline Aspek Konstruksi & 3,8 & 3,7 & 3,75 & 93,75 & Valid \\
\hline Aspek Bahasa & 3,8 & 3,7 & 3,75 & 93,75 & Valid \\
\hline Rerata & 3,8 & 3.7 & 3,7 & 92,5 & Valid \\
\hline
\end{tabular}

Selanjutnya soal-soal yang telah divalidasi diujicobakan, dan Hasil Nilai Siswa Pada Tes I dan Tes II ditunjukkan pada table Tabel 2, dan Deskripsi Spekulasi Siswa Dalam Menjawab Soal ditunjukkan pada Tabel 3 .

Tabel 2. Hasil Nilai Siswa Pada Tes I dan Tes II

\begin{tabular}{|c|c|c|c|}
\hline $\begin{array}{r}\text { No. } \\
\text { Subjek }\end{array}$ & $\begin{array}{c}\text { Tes I } \\
\text { (Nilai) }\end{array}$ & $\begin{array}{c}\text { Tes II } \\
\text { (Nilai) }\end{array}$ & Deskripsi \\
\hline I & 66,6 & 20,8 & Siswa ini melakukan spekulasi saat menjawab soal nomor 3, 9, dan II. \\
\hline 2. & 75 & 50 & Siswa ini melakukan spekulasi saat menjawab soal nomor 7 , dan IO. \\
\hline 3. & 91,6 & 83,3 & $\begin{array}{l}\text { Siswa ini tidak melakukan spekulasi, hanya saja Ia salah dalam menjawab } \\
\text { soal nomor } 8 \text { dan memilih yakin }(Y) \text { sehingga mendapatkan skor }-2\end{array}$ \\
\hline 4. & 91,6 & 58,3 & $\begin{array}{l}\text { Siswa ini melakukan spekulasi saat menjawab soal nomor } 1,6,7,8 \text {, I0, } \\
\text { dan II. }\end{array}$ \\
\hline 5. & 83,3 & $54, \mathrm{I}$ & $\begin{array}{l}\text { Siswa ini melakukan spekulasi saat menjawab soal nomor I, 2, 8, I0, dan } \\
\text { II. }\end{array}$ \\
\hline 6. & 91,6 & 50 & $\begin{array}{l}\text { Siswa ini melakukan spekulasi saat menjawab, kecuali soal nomor } 5,6 \text {, dan } \\
7 \text {. }\end{array}$ \\
\hline 7. & 83.3 & $4 \mathrm{I}, 6$ & $\begin{array}{l}\text { Siswa ini melakukan spekulasi saat menjawab, kecuali soal nomor 2, 5, 6, } \\
\text { dan } 7 \text {. }\end{array}$ \\
\hline 8. & 75 & 33,3 & $\begin{array}{l}\text { Siswa ini melakukan spekulasi saat menjawab, kecuali soal nomor 3, 5, 6, } \\
7 \text {, dan } 8 \text {. }\end{array}$ \\
\hline 9. & 66.6 & 20,8 & $\begin{array}{l}\text { Siswa ini melakukan spekulasi saat menjawab, kecuali soal nomor } 3,6,7 \text {, } \\
8 \text {, dan IO. }\end{array}$ \\
\hline IO. & 58.3 & 20,8 & Siswa ini melakukan spekulasi saat menjawab soal nomor 5, 9, I0, I I. \\
\hline II. & 83.3 & $29, \mathrm{I}$ & Siswa ini melakukan spekulasi saat menjawab, kecuali soal nomor 2 dan 6 . \\
\hline $\mathrm{I} 2$. & 75 & 20,8 & $\begin{array}{l}\text { Siswa ini melakukan spekulasi saat menjawab, kecuali soal nomor } 2,6 \text {, dan } \\
8 \text {. }\end{array}$ \\
\hline I3. & $9 \mathrm{I}, 6$ & 79 & Siswa ini melakukan spekulasi saat menjawab soal nomor 6 dan 7 . \\
\hline I4. & 83,3 & 45,8 & $\begin{array}{l}\text { Siswa ini melakukan spekulasi saat menjawab soal nomor I, 2, 7, 9, I0, } \\
\text { II, dan I2. }\end{array}$ \\
\hline I5. & 91,6 & $54, \mathrm{I}$ & Siswa ini melakukan spekulasi saat menjawab, kecuali soal nomor 3, 4, 6, \\
\hline
\end{tabular}


8, dan IO.

I6. 75

I7. 66,6

I8. 83,3

I9. 83,3

20. 91,7

2I. 66,6

22. 66,6

23. 66,6

24. 9I,6

25. 9I,6

26. $9 \mathrm{I}, 6$

27. $\quad 75$

28. $\quad 75$

29. $9 \mathrm{I}, 6$

30. 91,6

3I. $\quad 75$

32. 91,6
20,8

20,8

50

50

83,3

20,8

25

25

58,3

79

58,3

20,8

20,8

75

75

33,3

87,5
Siswa ini melakukan spekulasi saat menjawab soal nomor 4, 9, I0, II, dan I2.

Siswa ini melakukan spekulasi saat menjawab soal nomor 2, 5, 7, 9, II, dan $\mathrm{I} 2$.

Siswa ini melakukan spekulasi saat menjawab soal nomor I, 2, 8, II, dan I2.

Siswa ini melakukan spekulasi saat menjawab soal nomor I, 2, 7, I0, II, dan $\mathrm{I} 2$.

Siswa ini tidak melakukan spekulasi, hanya saja Ia salah dalam menjawab soal nomor IO dan memilih yakin ( $Y$ ) sehingga mendapatkan skor -2 .

Siswa ini melakukan spekulasi saat menjawab soal nomor 7, 9, I0, II, dan I2.

Siswa ini melakukan spekulasi saat menjawab soal nomor 7, 8, 9, I I, dan I2.

Siswa ini melakukan spekulasi saat menjawab soal nomor 3, 9, I0, II, dan I2.

Siswa ini melakukan spekulasi saat menjawab, kecuali soal nomor 3, 4, 5, 6, dan 9 .

Siswa ini melakukan spekulasi hanya pada soal nomor 6 .

Siswa ini melakukan spekulasi saat menjawab, kecuali soal nomor 3, 4, 5, 6 , dan 8.

Siswa ini melakukan spekulasi saat menjawab, kecuali soal nomor 2, 6, dan 8.

Siswa ini melakukan spekulasi saat menjawab soal nomor I, 7, 8, II, dan I2.

Siswa ini melakukan spekulasi saat menjawab soal nomor 6 dan 8 .

Siswa ini melakukan spekulasi saat menjawab soal nomor 8 dan II.

Siswa ini melakukan spekulasi saat menjawab soal nomor 2, 6, 7, 9, II, dan I2.

Siswa ini tidak melakukan spekulasi, hanya saja Ia memilih $T Y$ pada soal nomor IO sehingga mendapatkan skor -I.

Tabel 3. Data Spekulasi Siswa Dalam Menjawab Setiap Butir Soal

\begin{tabular}{lll}
\hline No & Spekulasi Siswa & Jumlah Siswa \\
\hline I & Tidak melakukan spekulasi & 3 orang \\
2 & Melakukan spekulasi pada I butir soal & I orang \\
3 & Melakukan spekulasi pada 2 butir soal & 4 orang \\
4 & Melakukan spekulasi pada 3 butir soal & I orang \\
\hline
\end{tabular}




\begin{tabular}{lll}
\hline 5 & Melakukan spekulasi pada 4 butir soal & I orang \\
6 & Melakukan spekulasi pada 5 butir soal & 7 orang \\
7 & Melakukan spekulasi pada 6 butir soal & 4 orang \\
8 & Melakukan spekulasi pada 7 butir soal & 6 orang \\
9 & Melakukan spekulasi pada 8 butir soal & I orang \\
I0 & Melakukan spekulasi pada 9 butir soal & 3 orang \\
II & Melakukan spekulasi pada IO butir soal & I orang \\
\hline
\end{tabular}

Dari hasil validasi oleh pakar evaluasi (VI) pada ranah materi diperoleh skor 3,9 dan pakar materi (V2) diperoleh skor 3,8, dengan rata-rata skor 3,85 dan persentase 96,25\%, dengan kriteria valid. Pada ranah konstruksi didapatkan rata-rata skor oleh (VI) dan (V2) yaitu 3,75 dengan presentase $93,75 \%$ dengan kriteria valid. Dan pada ranah bahasa didapatkan hasil sama seperti pada ranah konstruksi. Untuk rerata dari ketiga indikator (ranah materi, ranah konstruksi, ranah bahasa) mendapatkan nilai presentase sebesar 92,5\% dengan kriteria valid.

Selain itu terdapat juga masukan maupun komentar dari validator sebagai revisi kecil untuk menghasilkan produk yang valid. Setelah soal tersebut dinyatakan valid sehingga dapat diuji coba, maka langkah selanjutnya adalah uji coba produk. Uji coba dilakukan pada siswa SMP Negeri 4 Tondano khususnya kelas VIII A. Berdasarkan hasil uji coba, soal yang telah dikembangkan mampu meminimalisir spekulasi atau tebak-tebakan yang sering dilakukan oleh siswa saat menjawab soal objektif tipe benar-salah.

Jika dalam satu butir soal siswa memilih $B$ atau $S$ dan siswa tersebut yakin dengan jawabannya itu sehingga ia memilih $Y$. Jika jawaban tersebut benar maka skor untuk butir soal tersebut $=2$, dan jika jawaban tersebut salah maka skor untuk butir soal tersebut $=-2$. Jika siswa tersebut memilih $B$ atau $S$ dan siswa tersebut tidak yakin atau ragu-ragu dengan jawabannya sehingga ia memilih $T Y$. Jika jawaban tersebut salah maka skor untuk butir soal tersebut $=\mathrm{I}$, dan jika jawaban tersebut salah maka skor untuk butir soal tersebut $=-\mathrm{I}$.

Data hasil uji coba pada siswa yang didapatkan pada saat pelaksanaan tes I (soal yang belum dikembangkan) banyak siswa yang melakukan spekulasi saat menjawab soal. Siswa mendapatkan nilai yang tinggi atau mencapai KKM (Kriteria Ketuntasan Minimal) bukan karena siswa tersebut sudah memahami materi terkait soal yang Ia kerjakan, akan tetapi Ia hanya spekulasi atau menerka dalam menjawab. Tindakan menerka atau berspekulasi itu sendiri merupakan salah satu kelemahan dari bentuk soal objektif tipe benarsalah (Putra, 2013) [9]. Hal yang sama juga dikemukakan oleh Jihad dan Haris (2010) bahwa karena setiap siswa hanya memiliki dua pilihan untuk menjawab, yaitu benar atau salah, maka kemungkinannya hanya dua, yaitu 50\% benar atau 50\% salah walaupun dijawab dengan berspekulasi atau menerka [I0]. Atau dengan pernyataan lain kemungkinan jawaban siswa untuk menjawab benar sesuai dengan kunci jawaban, sama dengan kemungkinan jawaban siswa untuk menjawab salah sesuai dengan kunci jawaban. Hal ini perlu diperhatikan oleh calon guru, guru, maupun para ahli di bidang evaluasi pendidikan agar instrumen tes bentuk soal objektif tipe benar-salah perlu dikembangkan agar dapat meminimalisir tindakan berspekulasi atau menerka pada saat siswa menjawab soal, dan juga dapat mengukur tingkat pemahaman siswa pada materi terkait soal yang siswa kerjakan. Karena ketika siswa melakukan spekulasi, itu berarti siswa tersebut belum memahami materi terkait soal yang dikerjakan.

Data hasil uji coba pada tes II (soal yang telah dikembangkan) ternyata dapat mengungkapkan jawaban siswa yang didasarkan pada jawaban spekulasi dari siswa. Dari 32 orang siswa yang diuji coba didapatkan siswa yang melakukan spekulasi sebanyak 90,625\%. Dan untuk siswa yang tidak melakukan spekulasi sebanyak 9,375\%. Spekulasi yang dilakukan siswa beragam, ada siswa yang melakukan spekulasi hanya pada satu butir 
soal, dua butir soal, tiga butir soal, dan ada yang lebih dari tiga butir soal. Hal ini menunjukkan bahwa bentuk soal tipe Benar-Salah dengan pilihan Y-TY akan dapat meminimalisisr jawaban spekulasi atau menerka jawaban dari siswa.

Selain hasil uji coba kepada siswa, peneliti juga melakukan wawancara antara peneliti dan guru mata pelajaran IPA di kelas VIII A, guru tersebut mengatakan bahwa "soalnya menarik, karena selain pilihan B-S ada juga pilihan lain yaitu Y-TY. Dimana pemilihan Y-TY ini berfungsi untuk meminimalisir spekulasi atau tindakan menerka jawaban saat siswa menjawab soal. Pemilihan Y-TY juga dapat memberikan gambaran bahwa siswa tersebut sudah memahami ataupun belum memahami materi terkait soal yang dikerjakan. Bahkan dengan bentuk soal tipe Benar-Salah dengan pilihan Yakin atau Tidak Yakin akan mampu mengidentifikasi bahkan mengetahui dengan lebih akurat tentang kemampuan kognitif yang telah dimiliki oleh peserta didik atau siswa.

\section{Penutup}

Berdasarkan hasil penelitian, maka dapat disimpulkan bahwa soal benar-salah yang telah dikembangkan melalui 4 tahap (pendefinisian, perancangan, pengembangan dan penyebaran) dapat meminimalisir spekulasi siswa dalam menjawab soal. Dengan menggunakan bentuk soal B-S yang dilengkapi dengan pilihan Y-TY dapat mengukur pemahaman siswa secara lebih objektif dibandingkan dengan bentuk Soal B-S tanpa pilihan Y-TY. Dengan bentuk soal tipe Benar-Salah dengan pilihan Yakin atau Tidak Yakin [B - S ; Y - TY] akan mampu mengidentifikasi bahkan mengetahui dengan lebih akurat tentang kemampuan kognitif yang telah dimiliki oleh peserta didik atau siswa.

Melalui penelitian ini disarankan bagi para guru maupun penyusun soal agar dapat merancang soal bentuk B-S dengan pilihan Y-TY karena selain sangat efektif untuk meminimalisir tindakan spekulatif atau menerka dari siswa, juga dapat menghasilkan jumlah soal yang lebih banyak sehingga memenuhi prinsip komprehensif materi pembelajaran. Juga melalui penelitian ini merekomendasikan kepada para guru pada umumnya (tidak terbatas pada mata pelajaran IPA Fisika) tetapi dapat dikembangkan dan digunakan pada mata pelajaran lainnya

\section{Daftar Pustaka}

Arikunto, S., (2016), Dasar-Dasar Evaluasi Pendidikan, Bumi Aksara, Jakarta.

Jihad, A., dan Haris, A., (2010), Evaluasi Pemnbelajaran, Multi Pressindo, Yogyakarta.

Mardapi, D., (2014), Penilaian Otentik, Bahan Pelatihan pada Konferensi HEPI 20I4, Denpasar, I8 September.

Purjiyanto, E., Susanto, A., Cahyo, Babaro S., (2008), IPA Fisika Untuk SMP Kelas VIII, Erlangga, Jakarta.

Putra, Sitiatava R., (2013), Desain Evaluasi belajar Berbasis Kinerja, DIVA Press, Jogjakarta.

Sudaryono, (2012), Dasar-dasar Evaluasi Pembelajaran, Graha Ilmu, Yogyakarta.

Suwuhang, Ketlin F., (2018), Analisis Kecenderungan Mengerjakan Bentuk Tes Uraian dan Tes Objektif Materi Kinematika Gerak Pada Siswa Kelas X SMA Negeri I Tagulandang, Pendidikan Fisika. Fakultas Matematika Dan Ilmu Pengetahuan Alam. Universitas Negeri Manado, Tondano.

Thiagarajan, S., Semmel, Dorothy S., \& Semmel, Melvyn I., 1974, Instructional Development For Training Teachers Of Exceptional Children.: Leadership Training Institute/Special Education, University Of Minnesota, Mineapolis, Minnesota. 
JP3I (Jurnal Pengukuran Psikologi dan Pendidikan Indonesia), 8(2), 2019

Uno, Hamzah B., dan Koni, Satria, (2012), Assessment Pembelajaran, Bumi Aksara, Jakarta.

Widoyoko, Eko Putro, (2012), Evaluasi Program Pembelajaran, Panduan Praktis Bagi Pendidik dan Calon Pendidik, Pustaka Pelajar, Yogyakarta. 